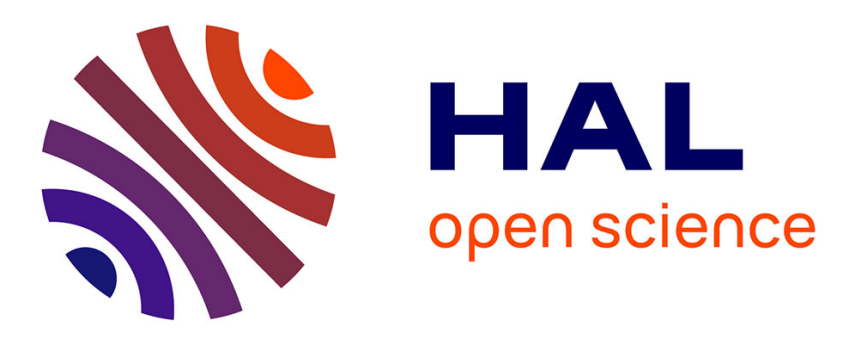

\title{
Applicability of image correlation techniques to characterise asymmetric refractory creep during bending tests
}

\author{
Gilles Dusserre, F. Nazaret, Laurent Robert, Thierry Cutard
}

\section{To cite this version:}

Gilles Dusserre, F. Nazaret, Laurent Robert, Thierry Cutard. Applicability of image correlation techniques to characterise asymmetric refractory creep during bending tests. Journal of the European Ceramic Society, 2013, 33 (2), pp.221-231. 10.1016/j.jeurceramsoc.2012.09.011 . hal-01687319

\author{
HAL Id: hal-01687319 \\ https://hal.science/hal-01687319
}

Submitted on 25 Oct 2018

HAL is a multi-disciplinary open access archive for the deposit and dissemination of scientific research documents, whether they are published or not. The documents may come from teaching and research institutions in France or abroad, or from public or private research centers.
L'archive ouverte pluridisciplinaire $\mathbf{H A L}$, est destinée au dépôt et à la diffusion de documents scientifiques de niveau recherche, publiés ou non, émanant des établissements d'enseignement et de recherche français ou étrangers, des laboratoires publics ou privés. 


\title{
Applicability of image correlation techniques to characterise asymmetric refractory creep during bending tests
}

\author{
G. Dusserre ${ }^{\mathrm{a}, *}$, F. Nazaret ${ }^{\mathrm{b}}$, L. Robert ${ }^{\mathrm{a}}$, T. Cutard $^{\mathrm{a}}$ \\ ${ }^{a}$ Université de Toulouse, Mines Albi, INSA, UPS, ISAE, ICA (Institut Clément Ader), Campus Jarlard F-81013 Albi Cedex 09, France \\ ${ }^{\mathrm{b}}$ Aurock, 54, rue Gustave Eiffel, 81000 Albi, France
}

\begin{abstract}
The design of fibre reinforced refractory castable structures for high temperature applications requires the characterisation of the material creep behaviour. As many other heterogeneous ceramics, these materials creep faster under tensile stresses than under compressive ones because of the motion of hard particles in a soft matrix. Bending tests have been performed to characterise the creep behaviour of the considered material, and 3D digital image correlation is used to obtain strain fields after interrupted tests. The position of the neutral axis, defined here from the residual inelastic strain field, allows to highlight the asymmetry of creep and to evaluate the asymmetry ratio.
\end{abstract}

Keywords: Creep; Refractories; Mechanical properties; Asymmetry tension-compression; 3D Digital Image Correlation

\section{Introduction}

Fibre reinforced refractory castables are suitable materials for structures undergoing high thermal exposure. Above $1200^{\circ} \mathrm{C}$ creep mechanisms occur in the material even under low stresses. The creep behaviour characterisation of these materials is therefore mandatory to design such structures. As it is the case for most of the materials, the creep of ceramics can generally be divided into three steps. ${ }^{1}$ This complex behaviour is the result of many possible mechanisms ${ }^{1}$ as for examples, grain boundary sliding, ${ }^{2}$ diffusion, dislocation motion, viscous flow, cracking and cavitation or grain growth. ${ }^{3}$ The first step involves nonlinear creep mostly related to micro-cracking and micro-porosity cavitation. ${ }^{4}$ A stationary creep step takes place subsequently (second step) until macro-damage occurs and accelerates the creep $^{1}$ (third step).

Due to an easy processing at high temperature, bending tests are usually chosen to characterise this behaviour for refractories, involving a stress redistribution as a result of non-linear behaviour and non-uniform loading. ${ }^{5}$ Moreover heterogeneous ceramics at high temperature exhibit an asymmetric behaviour

\footnotetext{
* Corresponding author. Tel.: +33 563493309; fax: +33 563493242.

E-mail address: gilles.dusserre@mines-albi.fr (G. Dusserre).
}

due to preferential damage ${ }^{4}$ or cavitation ${ }^{6,7}$ in tension and/or related to the motion of hard particles in a glassy matrix ${ }^{8}$ leading the material to creep faster in tension than in compression.

Due to the difficulty to perform tension experiments at high temperature, ${ }^{7,9}$ many works have been carried out in order to study the creep of ceramics in tension by using bending tests 4,10 in order to complete compressive characterisation data. If the experimental procedure is therefore simplified, data processing is significantly more difficult due to the non-uniform state of stress involved in the specimen. Moreover bending tests involve both tension and compression whose effects cannot be discriminated by processing the usual test data without new specific assumptions, for instance by neglecting the compressive creep $^{11,12}$ or assuming that the maximal asymptotical tension stress $^{13}$ is the same as in the symmetric case. ${ }^{14}$ Most of the studies $^{10-13,15,16}$ assume a steady state creep law. For materials exhibiting a strong primary creep behaviour, this assumption is only relevant under uniaxial loading. Under bending conditions, the primary creep strongly affects the stress redistribution and cannot be neglected if the material undergoes a pronounced primary creep.

Interesting attempts have been proposed to characterise the asymmetrical creep behaviour from only bending tests. Talty and Dirks $^{15}$ performed bending tests on trapezoidal cross-section beams. Depending on the orientation of the specimen (larger 
surface under tension or compression), the ratio between the cross section area under compression and under tension was modified. The difference between the creep of the specimen oriented within one direction or the other is then due to the asymmetric behaviour. Both tensile and compressive stationary creep characteristics were obtained through an analytical model.

The other way investigated to characterise asymmetrical creep from bending data is based on the location of the neutral axis of the beam which diverges from the mid-plane of the specimen when asymmetrical creep occurs. This effect, studied from an analytical point of view by Chuang, ${ }^{17}$ inspired some experimental studies. Wiederhorn et al., ${ }^{18}$ then Chen and Chuang ${ }^{16}$ measured the neutral axis position by using indentations made on the specimen along two parallel lines perpendicular to the specimen length. This parameter was used as an index of the asymmetry and permitted an analytical estimation of tensile and compressive creep parameters from a single bending test.

In order to assess the location of the neutral axis, it is proposed in the present study to use 3D-Digital Image Correlation (3D-DIC) to perform full-field strain measurements. This experimental method was successfully used to characterise the behaviour of ceramics undergoing small strains. For example, elasticity and damage were studied during bending tests at room temperature. ${ }^{19,20}$ High temperature contactless measurement data are also available in the literature. They have been obtained by 2D-DIC to measure large tensile strains using an alumina powder suspension sprayed speckle. ${ }^{21}$ Small strains can be also measured by video extensometer even at ultra-high temperature, ${ }^{22}$ but only mean strains are provided over the investigated area.

This study reports experimental results obtained using 3DDIC method, that highlight the asymmetric creep behaviour at high temperature from a single bending experiment. Full-field strain data were measured after interrupted four-point bending tests, emphasising that the neutral axis is not located in the midplane of the specimen. The neutral axis is defined in this case by the location where the residual inelastic strain is zero, which differs from the zero-stress plane as will be discussed further in the paper. A faster creep in tension results in a neutral axis shifted towards the initially compressed volume.

\section{Materials and methods}

\subsection{Fibre reinforced refractory castable}

The studied material is a commercial ultra low cement bauxite castable (Table 1) constituted of bauxite aggregates dispersed in a matrix, Fig. 1. The aggregates size is between 0.2 and $5 \mathrm{~mm}$ diameter, see in Fig. 2 the size distribution histogram obtained from image analysis. The matrix is not homogeneous since it is composed of small bauxite particles (diameter lower than $200 \mu \mathrm{m}$, Fig. 1a) and contains $8 \mathrm{wt} . \%$ of a calcium alumina cement, fumed silica and $\alpha$-alumina. ${ }^{23}$ The castable is reinforced with $2 \mathrm{wt}$.\% FeCrAl hooked-end fibres (length $25 \mathrm{~mm}$, diameter $0.7 \mathrm{~mm}$, Fig. 1b). The major role of these fibres is to prevent macro-crack propagation and to weaken the brittle behaviour of the refractory material. Despite a careful
Table 1

Chemical composition and properties of the refractory castable. ${ }^{23}$

\begin{tabular}{|c|c|}
\hline Component/property & Composition/value \\
\hline $\mathrm{Al}_{2} \mathrm{O}_{3}($ wt. $\%)$ & 85 \\
\hline $\mathrm{SiO}_{2}($ wt. $\%)$ & 10 \\
\hline $\mathrm{CaO}($ wt.\%) & 1.1 \\
\hline $\mathrm{Fe}_{2} \mathrm{O}_{3}($ wt. $\%)$ & 1 \\
\hline Water requirement (wt.\%) & $4.2-5.2$ \\
\hline Open porosity (vol.\%) & 10 \\
\hline Apparent density $\left(\mathrm{kg} \mathrm{m}^{-3}\right)$ & 2970 \\
\hline Aggregate type & Mainly bauxite \\
\hline Aggregate size (mm) & $0.2-5$ \\
\hline
\end{tabular}
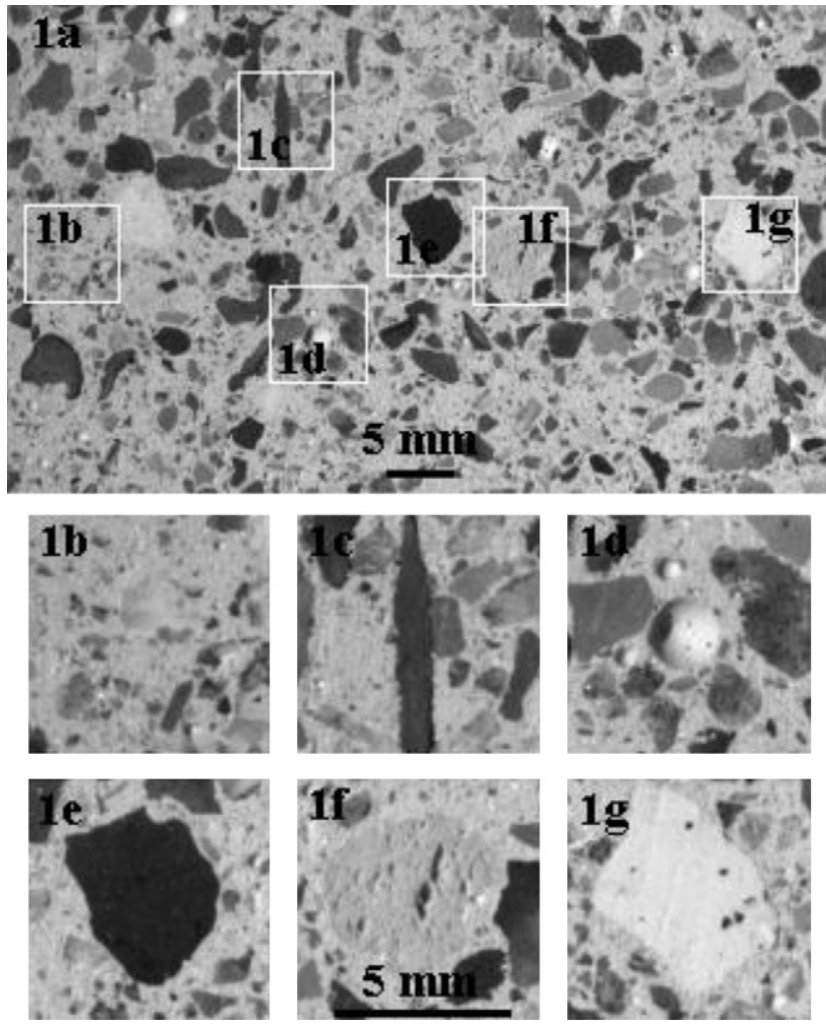

Fig. 1. Material surface texture (1a): small aggregates in the matrix (1b), fibre (1c), void (1d), aggregate (1e), bauxite aggregates (1f and $1 \mathrm{~g}$ ).

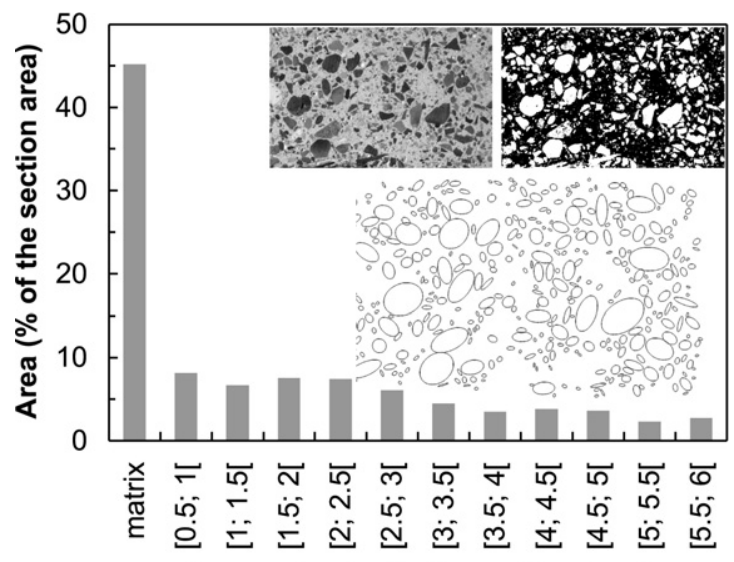

Aggregate size in the section $(\mathrm{mm})$

Fig. 2. Histogram of the aggregates size distribution (from image analysis). 
manufacture of the specimen, it turns out that porosities remain inevitably in the material, Fig. 1c. However these defects are not numerous, are spherical (involving low stress concentration) and their diameter does not exceed a few millimetres. Their influence on the mechanical behaviour will then be neglected. Nevertheless these defects cause problems for 3D-DIC measurements since they create shadows that are not similar depending on the view point of the cameras. The effect of the material heterogeneity, as aggregates distribution, in a single specimen and between two specimens, will not be discussed. The largest aggregates are characterised by a $5 \mathrm{~mm}$ diameter (Fig. 1d-f) and their grinded surfaces show a bulk porosity favourable to the cohesion with the matrix. Aggregates are mainly bauxite based ones. Other ones come from an oxide grog which is added in the concrete formulation.

The $35 \mathrm{~mm} \times 40 \mathrm{~mm} \times 165 \mathrm{~mm}$ specimens were cast under vibrations and hardened at room temperature for $24 \mathrm{~h}$ before taking out from the mould. They were then dried at $110^{\circ} \mathrm{C}$ for $24 \mathrm{~h}$ and then fired at the test temperature for $30 \mathrm{~h}$. The four sample faces were finally ground in order to provide parallel and plane bearing faces while bending, and overall to reveal the texture of the surface, necessary to perform 3D-DIC measurement on a specimen subjected to high temperature (in the absence of artificially added speckle pattern sufficiently tough and inert up to $1200^{\circ} \mathrm{C}$ ).

\subsection{Four-point bending creep tests}

The tests have been performed using a $50 \mathrm{kN}$ MTS 810 servohydraulic universal testing machine fitted out with a resistive furnace, a four-point bending setup made out of alumina and silicon carbide parts, a $5 \mathrm{kN}$ load cell and a LVDT sensor located at the middle of the lower face in order to measure the specimen deflection during creep, Fig. 3.

After locating the specimen on the bending setup, a heating rate of $250{ }^{\circ} \mathrm{Ch}^{-1}$ was applied until the test temperature. Once a steady temperature is achieved, a constant vertical displacement rate $\left(0.2 \mathrm{~mm} \mathrm{~min}^{-1}\right)$ was applied to the upper roller holder until the creep load is reached. For creep experiment, the constant creep load was then applied up to the failure of the specimen. For interrupted creep tests, the creep load was applied until a deflection of $0.2 \mathrm{~mm}$. The specimen was then unloaded and cooled down to room temperature, at a rate of $200{ }^{\circ} \mathrm{Ch}^{-1}$. The LVDT sensor records the beam deflection $(\delta)$ during elastic spring-back as well as during the inelastic relaxation of the material once unloaded. The test conditions of the different experiments are summarised in Table 2, where nominal stress $\left(\sigma_{\text {nom }}\right)$ and strain $\left(\varepsilon_{\text {nom }}\right)$ are calculated as the maximal value obtained using the theory of elasticity (Eqs. (1) and (2)) where $P$ is the applied load, $L$ and $l$ are respectively the distance between the lower and upper rollers, $b$ and $h$ are respectively the specimen width and height, see Fig. 3. An apparent bending modulus, $E_{a p p}$ was evaluated during the loading using Eq. (3), where $\Delta$ denotes a variation of the concerned variable. A creep characterisation was first performed at $1030{ }^{\circ} \mathrm{C}$, but the specimen underwent significant damage in the tensile area even for low stresses. Moreover stresses sufficiently low to prevent cracking would lead to unreasonable experiment duration. That is the reason why a test was performed at $1200^{\circ} \mathrm{C}$ in order to reduce the stress applied as well as the creep test duration.

$$
\begin{aligned}
\sigma_{\text {nom }} & =\frac{3 P(L-l)}{2 b h^{2}} \\
\varepsilon_{\text {nom }} & =12 h \delta \frac{L-l}{2 L^{3}-3 l^{2} L+l^{3}} \\
E_{\text {app }} & =\frac{3}{b h^{3}} \frac{\Delta P}{\Delta \delta}\left(\frac{L^{3}}{12}-\frac{l^{2} L}{8}+\frac{l^{3}}{24}\right)
\end{aligned}
$$

\section{Full-field strain measurements}

DIC is now a well known technique in the field of experimental mechanics ${ }^{24}$ and its principle will not be presented here. 3D-DIC at high temperature encounter different technical problems that limit its use to high strain measurements. Except in vacuum, the convective effects linked to the spatially variation of the refraction index around the specimen create image distortions that cannot be corrected yet. ${ }^{25}$ Moreover, adding an artificial controlled speckle pattern requires a coating material that remains tough and inert up to $1200^{\circ} \mathrm{C}$, what is especially difficult to find in the present case where the specimen is porous and undergoes intermediate strains. ${ }^{21}$ Finally, at high temperature, visible thermal radiation emitted by the specimen is brighter than the white light source that is used to illuminate the sample. ${ }^{26}$

It was then possible to get around these three problems by performing interrupted tests in order to measure the kinematical fields at room temperature. Indeed the studied material has a naturally textured surface that allows to perform 3D-DIC without adding artificial speckle pattern. Note that this approach is possible only because the 3D-DIC technique, theoretically insensitive to rigid body motions, was used instead of standard (2D-)DIC, although the surface of the specimen was planar.

On the one hand, the advantage was the possibility to snap several images of the same strain state in order to decrease the CCD noise by averaging grey levels, as emphasised by. ${ }^{27}$ Indeed it has been shown in Ref. 28 that the standard deviation of the displacement error in DIC $\left(\sigma_{u}\right)$ can be estimated by Eq. (4) when the mismatch error between the strain of the subset and the actual strain is negligible (e.g. for small strains). ${ }^{29}$

$\sigma_{u} \propto \frac{\sigma_{n}}{d \sqrt{\overline{\nabla f}^{2}}}$

where $\sigma_{n}$ is the standard deviation of the actual image noise, $\overline{\nabla f}^{2}$ the average of the squared grey level gradients in the image and $d$ the subset size. This will be detailed further.

On the other hand, due to the testing device configuration, 3DDIC could not be performed on the testing machine. A separate positioning setup was necessary to ensure a reliable specimen position before and after creep. Let us note however that an additional measurement uncertainty can be introduced by the specimen repositioning. Nevertheless this measurement uncertainty is expected to be low because rigid body motion can be removed by $3 \mathrm{D}-\mathrm{DIC}$. 


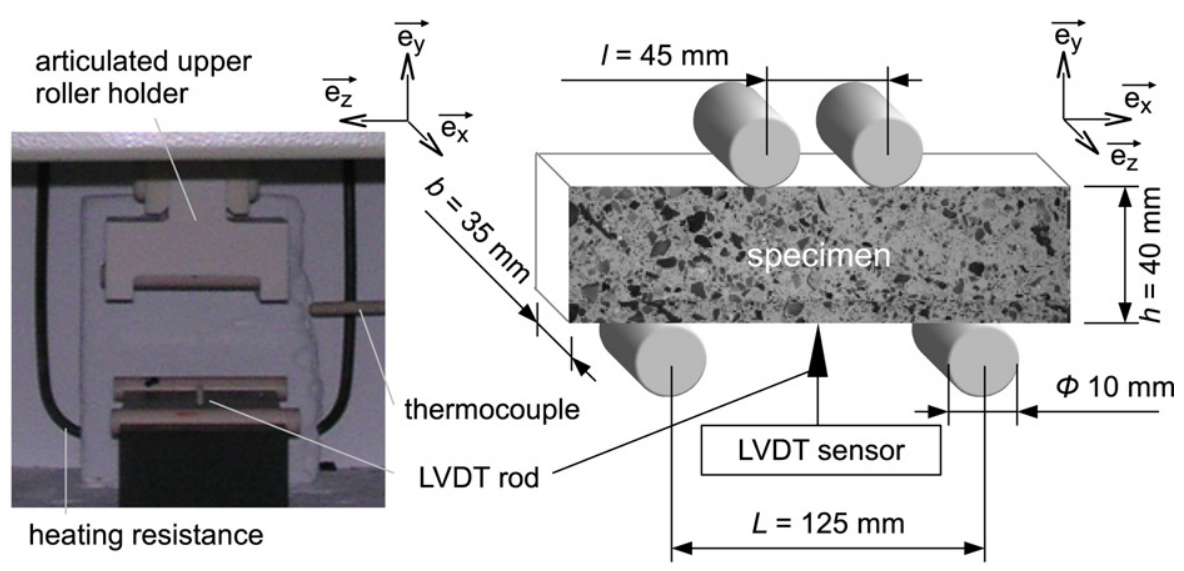

Fig. 3. High temperature four-point bending setup.

Table 2

Creep experiment conditions.

\begin{tabular}{llrr}
\hline Specimen & Test procedure & $T\left({ }^{\circ} \mathrm{C}\right)$ & $\sigma_{\text {nom }}(\mathrm{MPa})$ \\
\hline 1 & Monotonic & 1017 & $0-4936$ \\
2 & Creep & 895 & 3488 \\
3 & Creep & 1030 & 710 \\
4 & Creep & 1030 & 2220 \\
5 & Creep & 1030 & 2870 \\
6 & Creep & 1030 & 3560 \\
7 & Interrupted creep & 1031 & 1680 \\
8 & Interrupted creep & 1031 & 2890 \\
9 & Interrupted creep & 1031 & 8 \\
10 & Interrupted creep & 1197 & 4 \\
11 & Creep & 1200 & 400 \\
\end{tabular}

\section{1. $3 D-D I C$ setup}

The stereo-rig is constituted by two 8-bits Pike ${ }^{\circledR}$ Allied Vision Technology CCD digital cameras (resolution $1388 \times 1036$ pixels, lenses M5 Fujinon $50 \mathrm{~mm}$ f1:2.3) located with a vergence angle of $9.7^{\circ}$ between the two focal axis. The area of interest was set to approximately $130 \mathrm{~mm} \times 40 \mathrm{~mm}$, which defines a typical magnification factor of 10.3 pixel $\mathrm{mm}^{-1}$. A roller holder similar to the lower one of the bending setup was used to support the specimen during image acquisition. The specimen was located carefully before each full-field measurement in order to reduce the repositioning dispersion and avoid to modify the focusing between two measurements. For each measurement, 25 images were snapped with an integration time of $4 \mathrm{~ms}$.

\subsection{Relevance of the natural texture of the material}

Fig. 4 describes the natural texture of the material and the different patterns around several details. If an homogeneous distribution of grey levels could be observed on the whole area of interest, it turns out from the study of the grey level histograms for each detail, that this distribution is the consequence of a wide variety of aggregate colours. This results in high grey level gradients around the aggregates, what is suitable for DIC processing, see Eq. (4). Nevertheless these high grey level gradients are located at the interface between the aggregates and the matrix, i.e. areas with high material properties heterogeneities. The image correlation is then made easier thanks to high grey level gradients, however mismatch errors are increased because local subset transformations are not accurate enough to catch the actual strain gradients induced by material heterogeneities. In fact, the major problem encountered was a non-conservation of the optical flow in the vicinity of the fibres, due to a texture change induced by oxidation, or resulting from dissociation between the fibre and the castable. As a result, the correlation could not be performed in these few small areas.

\subsection{D-DIC parameters}

Vic-3D ${ }^{\circledR}$ software ${ }^{30}$ was used to carry out the calibration, to process the images and to perform the full-field strain calculation. DIC principle uses an optimisation algorithm to find the parameters of the correlation window (subset) shape function that best matches the deformed subset once applied to the unstrained subset. The Vic-3D ${ }^{\circledR}$ software only allows a firstorder strain mode of the subset. Therefore the size of the subset should be chosen small enough to allow a reasonable linear approximation of the actual displacement field. An error referred to as the "mismatch error" 29 will be made in the present case because a non-uniform stress field is applied to an heterogeneous material that does not behave linearly. The linear model is then not everywhere relevant to match properly the actual 

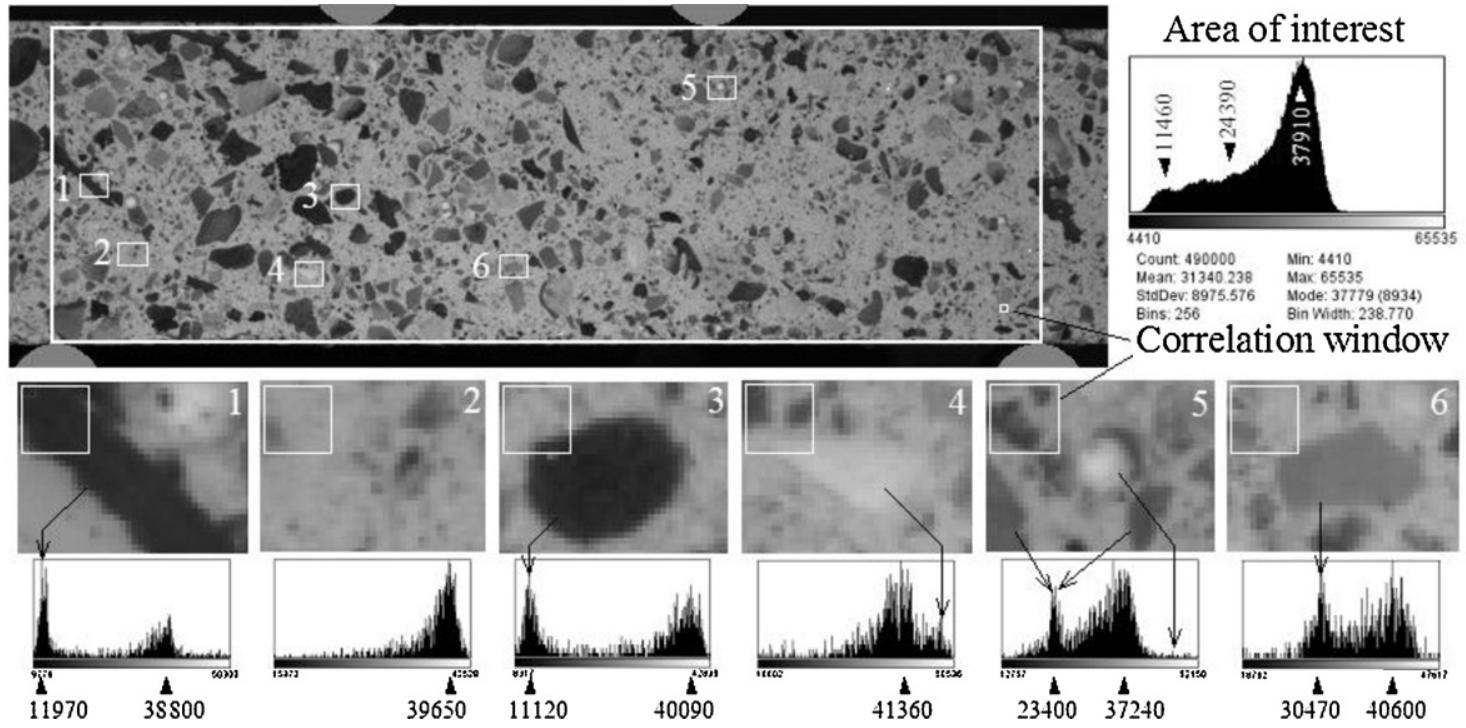

Fig. 4. Natural speckle pattern in the area of interest. Some histograms linked to the details 1-6 are presented with the correlation window.

displacement field. That is why a particular attention was paid to the diminution of the subset size.

Following Eq. (4), the uncertainty in the displacement measurement can be improved by decreasing the image noise by averaging $N$ images $\left(\sigma_{n}\right.$ is divided by $\sqrt{N}$ ), and by increasing the grey level gradients and the subset size. Increasing the latter leads to reduce the spatial resolution and to increase the mismatch error which is critical in such a case of heterogeneous material showing large local strain gradients. Moreover in the present case grey level gradients result from image characteristics and the natural texture cannot be optimised. Performing image acquisition on a static specimen allows to snap in each configuration 25 images of the same strain state. The mean grey level value calculated on each pixel over all the 25 images gives a new image coded in 16 bits with a reduced noise, $\sigma_{n} / 5$. The uncertainty in the displacement measurement being proportional to the image noise and inversely to the subset size, Eq. (4), it is therefore chosen the smallest subset size that still gives good matching results. However the subset size must be large enough to contain sufficient grey level information. A $15 \times 15$ pixels subset size was found to be a relevant compromise. The step size (pitch of the grid of correlated points) is 3 pixels, and the grey level interpolation was performed using 4-tap splines. Engineering strains were calculated using the displacement field resulting from DIC with a filter size (square optical gauge length) of $15 \times 15$ correlated points, namely $45 \times 45$ pixels corresponding to a strain spatial resolution of about $4.5 \mathrm{~mm}$.

\subsection{Experimental 3D-DIC error assessment}

Compared to the 2D-DIC, the 3D-DIC method is theoretically insensitive to sample rigid body motion. Nevertheless, a rigid body motion, especially rotation, still may imply small errors in correlation computation and then in strain calculation. For that reason, the locating of the specimen was made very carefully before and after creep. Nevertheless the deformation of the specimen makes it difficult to ensure a perfect repositioning. To assess the error due to repositioning, several images of the unstrained specimen have been acquired after removing and repositioning it on the specimen holder according to the same procedure. In each case a total of 25 frames were taken in order to average the images and decrease the errors from image noise. Noise from the images was evaluated to about 1.25 grey level over 256 , which is usual for this kind of CCD camera. To verify the effect of averaging images, a no-motion (or noise floor) experiment was first performed: images were acquired during time without any motion of the specimen, averaged or not, then computed by the DIC software with parameters as described previously. A second set of images were acquired after a repositioning of the same unstrained specimen. Results are summarised in Table 3. Only the horizontal displacement (denoted $u_{x}$ ) and the transversal strain (denoted $\varepsilon_{x x}$ ) are reported in the table. The actual value of all these data is zero excepted $u_{x}$ for the images taken after a rigid body motion. Such an analysis without physical deformation of the speckle pattern gives a lower bound of the standard displacement and strain uncertainties.

As expected, the displacement standard deviation is reduced by 5 and consequently also the strain standard deviation if averaged images are considered. The strain bias (mean value) is also weakly affected by the averaging. The repositioning leads to a strain standard deviation of $2.0 \times 10^{-4}$ which is almost of the same order of those provided by image noise if images are not averaged, showing the benefit to average images and take care when repositioning.

To summarise, the values that could be associated to the standard uncertainties are slightly more than $1 \mu \mathrm{m}$ (about $1 / 100$ pixel) and $2.0 \times 10^{-4}$ respectively for the displacement and strain. If averaged images are used, rigid body motion leads to a more dispersed strain field (higher standard deviation) than no-motion without affecting the mean value. 
Measurement errors estimated from no-motion (noise floor) and no-strain repositioning (rigid body motion) experiments.

\begin{tabular}{|c|c|c|c|c|}
\hline & Mean $u_{x}$ & Standard dev. $u_{x}$ & Mean $\varepsilon_{x x}$ & Standard dev. $\varepsilon_{x x}$ \\
\hline No motion (noise floor) & $0.6 \mu \mathrm{m}$ & $1.5 \mu \mathrm{m}$ & $1 \times 10^{-5}$ & $2.7 \times 10^{-4}$ \\
\hline Not averaged images & & & & \\
\hline $\begin{array}{l}\text { No motion (noise floor) } \\
\text { Averaged images }\end{array}$ & $1 \mu \mathrm{m}$ & $0.3 \mu \mathrm{m}$ & $4 \times 10^{-6}$ & $4.9 \times 10^{-5}$ \\
\hline $\begin{array}{l}\text { Undeformed specimen (rigid } \\
\text { body motion) } \\
\text { Averaged images }\end{array}$ & $8 \mu \mathrm{m}$ & $1.1 \mu \mathrm{m}$ & $4 \times 10^{-6}$ & $2.0 \times 10^{-4}$ \\
\hline
\end{tabular}

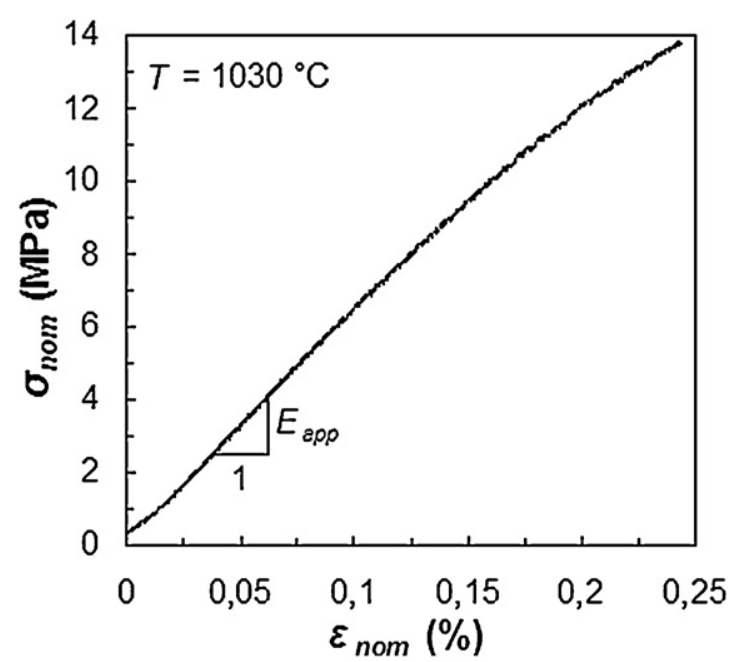

Fig. 5. Monotonic bending behaviour of the bauxite castable at $1030^{\circ} \mathrm{C}$ (specimen 1).

From the previous discussion about the quality of the fullfield strain measurement, it turns out that many difficulties are encountered in the present case to obtain accurate results: high material heterogeneity, non-linear mechanical behaviour, nonuniform state of stress, repositioning of the specimen between two image snaps, local non-conservation of the optical flow. To get around these difficulties, averaged images were used and a very careful repositioning was performed allowing to minimise as much as possible strain uncertainties.

The following section details the creep behaviour of the material and analyses the measured strain fields to locate the neutral axis and provide an interpretation of the stress redistribution induced by the asymmetrical creep flow in bending.

\section{Experimental results}

\subsection{Monotonic bending behaviour at $1030^{\circ} \mathrm{C}$}

This section presents the behaviour of the material under fourpoint bending loading at high temperature. A monotonic test at $1030{ }^{\circ} \mathrm{C}$ illustrates the behaviour of the material up to failure, see Fig. 5. The material exhibits a quasi brittle behaviour even at high temperature. At $1030{ }^{\circ} \mathrm{C}$, its apparent Young's modulus, measured in bending, ${ }^{31}$ is $6.5 \mathrm{GPa}$ and the failure arises at $14 \mathrm{MPa}$. Above $8 \mathrm{MPa}$, a weak discrepancy to a linear behaviour appears due to micro-damaging and to viscoplasticity. For that

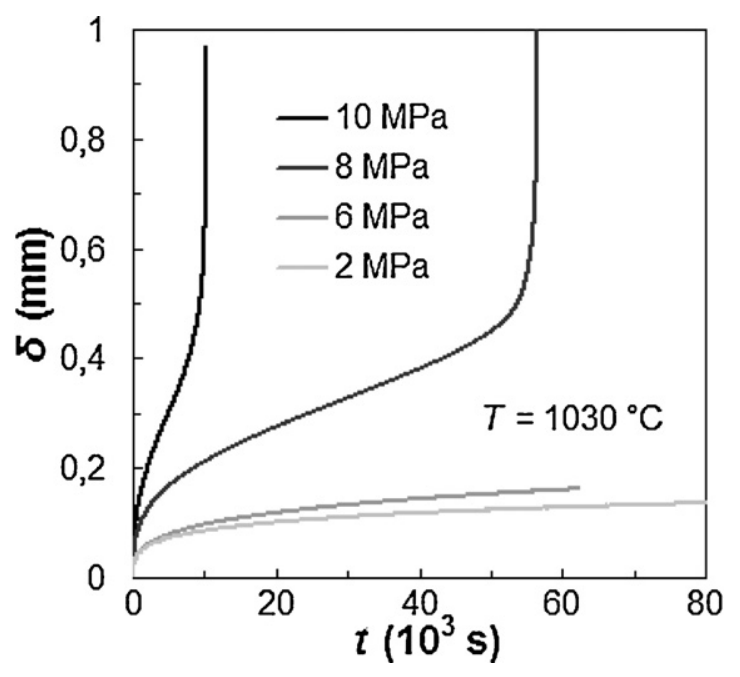

Fig. 6. Four-point bending creep curves at $1030{ }^{\circ} \mathrm{C}$ of the bauxite castable between 2 and $10 \mathrm{MPa}$ (the origin of the graph is the beginning of the creep step, just after the loading) (specimens 3, 4, 5 and 6).

reason the creep tests were performed under nominal stresses lower than $8 \mathrm{MPa}$.

\subsection{Creep behaviour from 900 to $1200^{\circ} \mathrm{C}$}

Creep tests were performed from 900 to $1200^{\circ} \mathrm{C}$ under nominal stresses from 1 to $10 \mathrm{MPa}$. The creep of the considered bauxite castable is characterised by a three-step behaviour with a wide primary creep domain followed by a narrow stationary domain. The third step involves cracking leading to the failure of the specimen. This behaviour is strongly dependent to stress, for example at $1030{ }^{\circ} \mathrm{C}$ in Fig. 6 . The nominal strain rate $\dot{\varepsilon}_{\text {nom }}$ in the stationary range is plotted against the nominal stress in Fig. 7. A corresponding apparent nominal stress exponent of 7.24 is deduced, Fig. 7. This high value may indicate the occurrence of damage during the tests. A strong temperature dependency is also observed.

\subsection{Strain fields at $1030^{\circ} \mathrm{C}$}

Full-field strain measurements were performed after interrupted tests. As illustrated in Fig. 8, the measured strain fields correspond to a stress state after elastic unloading and viscous relaxation. Four kinematical fields were measured after tests under 2, 4 and $8 \mathrm{MPa}$. Displacement/strain fields presented in Fig. 9 corresponds to the points A, B, C and D of the creep 


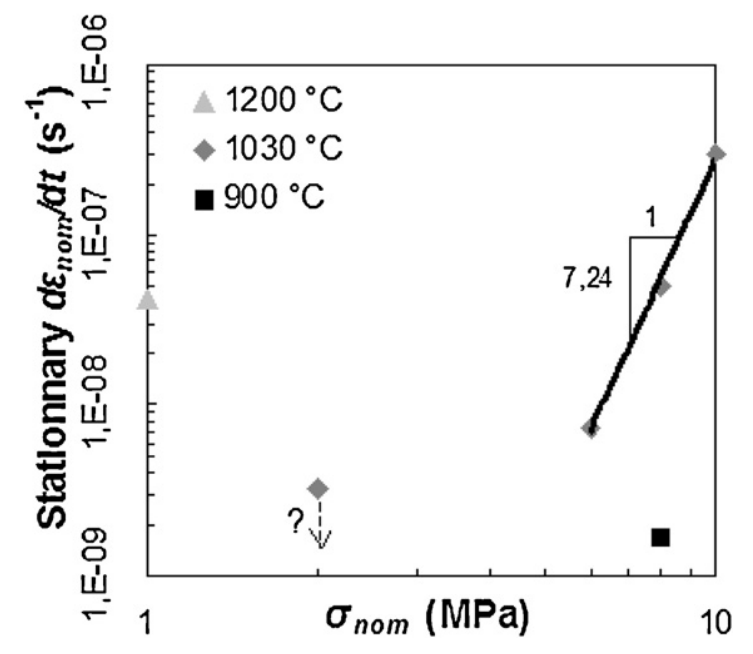

Fig. 7. Nominal strain rate measured in the stationary range as a function of the nominal stress (for the point at $1030^{\circ} \mathrm{C}$ and $2 \mathrm{MPa}$ the tertiary creep was not achieved, thus it is not sure that the measurement was made in the stationary range) (specimens 2, 3, 4, 5, 6 and 11)

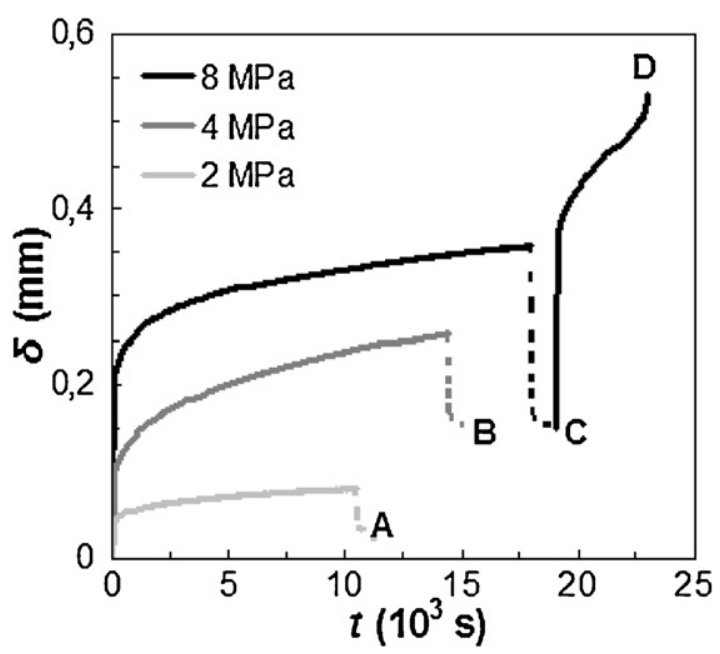

Fig. 8. Four-point bending creep curves at $1030^{\circ} \mathrm{C}$ obtained from interrupted tests (the origin of the graph corresponds to the beginning of each test, before the loading) (specimens 7,8 and 9).

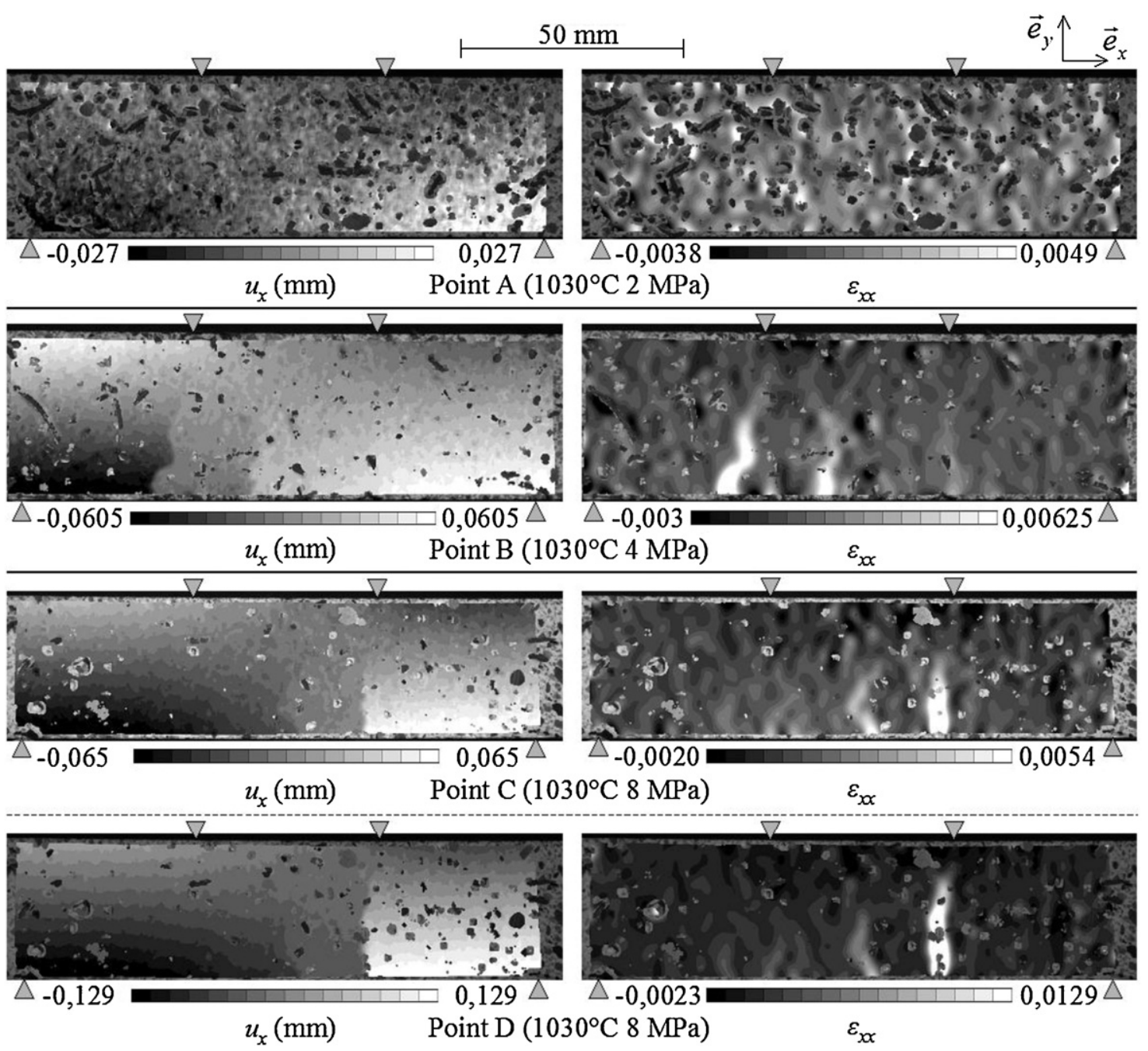

Fig. 9. Horizontal displacement fields (left) and longitudinal strain fields (right) measured at room temperature after creep at $1030{ }^{\circ} \mathrm{C}$ (specimens 7,8 and 9 ). 


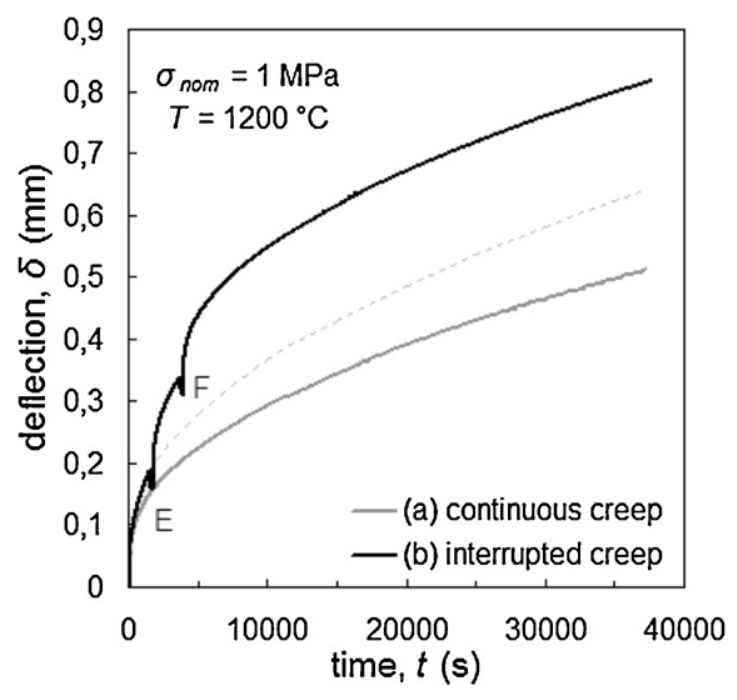

Fig. 10. Creep curves at $1200^{\circ} \mathrm{C}$ obtained during continuous (a) and interrupted tests (b), respectively, of specimens 11 and 10 (the origin of the graph is the beginning of the test, before the loading).

curves plotted in Fig. 8. The points A, B and C are representative of the material at the beginning of the stationary creep. The point $\mathrm{D}$ is representative of the stress state after the specimen failure. It is noteworthy that the failure of the specimen under $8 \mathrm{MPa}$ (point D) was significantly accelerated by the test interruption as deduced from the comparison of both curves at $1030^{\circ} \mathrm{C}$ and $8 \mathrm{MPa}$ of Figs. 6 and 8 .
The displacement/strain fields measured at points A, B, C and $\mathrm{D}$ are depicted in Fig. 9. The method is not accurate enough to measure the very low displacements involved by creep tests performed under $2 \mathrm{MPa}$ (point A), as discussed in Section 3.4. The discontinuous displacement field along the horizontal axis, $u_{x}$, shows that the specimens at points B, C and D already undergo damage despite quite small creep deflections. The propagation of the largest crack from point $\mathrm{C}$ to point $\mathrm{D}$ involves a stress redistribution that results in a closure of the crack at the middle of the specimen. The large asymmetric strains observed are mainly due to cracking phenomena and do not allow to conclude on the asymmetry of creep. Indeed the strain in the cracked area does not have a physical sense and only results from the discontinuity in the displacement field. It is thus necessary to perform a creep test at higher temperature under very low stress to avoid damage occurrence and get sufficient displacement amplitude after unloading to obtain reliable full-field measurements. Nevertheless these results highlight the usefulness of this technique to monitor the mechanical experiments.

\subsection{Strain fields at $1200^{\circ} \mathrm{C}$}

Fig. 10 compares the creep curves of two specimens undergoing respectively a continuous creep (a) and a discontinuous creep (b), under a nominal bending stress of $1 \mathrm{MPa}$ at $1200^{\circ} \mathrm{C}$. Before the first unloading (point $\mathrm{E}$ in Fig. 10), both specimens exhibit a similar behaviour despite a significant gap between

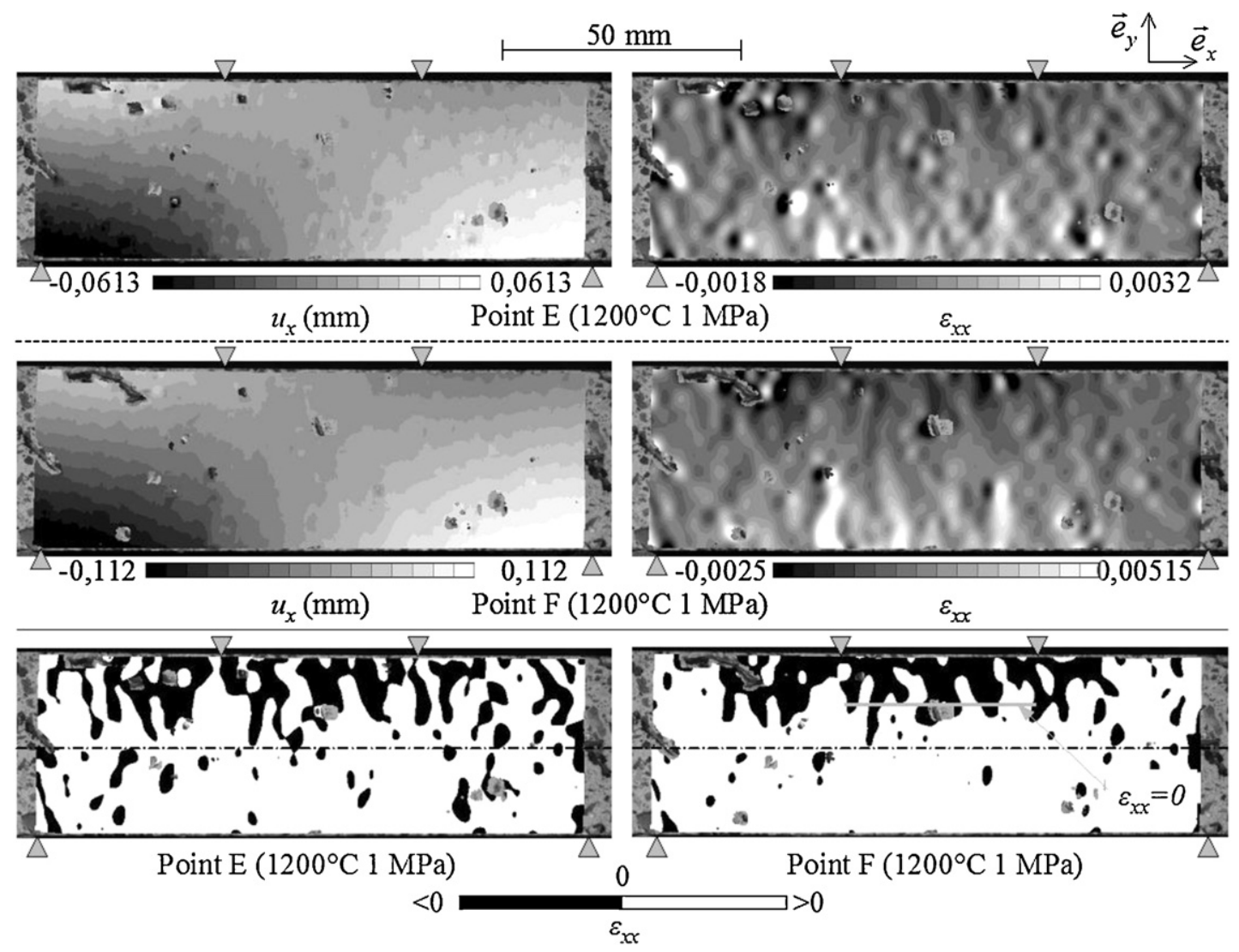

Fig. 11. Displacement and strain fields measured at points $\mathrm{E}$ and $\mathrm{F}$ after respectively 25 and $50 \mathrm{~min}$ of creep under $1 \mathrm{MPa}$ at $1200^{\circ} \mathrm{C}$ (specimen 11 ). 
the curves, related to material heterogeneity. In the first creep domain, both curves can be superimposed by scaling the deflection value of the continuous creep (in this case by a factor of 1.25). The curve in dashed line in Fig. 10 is thus obtained by performing an extrapolation of the continuous creep behaviour of the specimen (b). It is noteworthy that after the second and the third loadings, a strongly non linear creep was observed. This may be attributed to a primary creep mechanism related to the motion of hard particles in a soft matrix. When relaxation occurs, the residual stresses allow to recover an internal structure of the material without contact between the particles, allowing again the primary creep state to occur. A closure of the micro-cracks during residual stresses relaxation can also contribute to such a behaviour. Finally it is reported that, during this test at $1200{ }^{\circ} \mathrm{C}$ under low stresses, the deflection related to the spring-back effect is significantly low compared to the creep deflection.

Fig. 11 shows the residual displacement/strain fields measured on the specimen at points $\mathrm{E}$ and $\mathrm{F}$, respectively after 25 and $50 \mathrm{~min}$ of creep under $1 \mathrm{MPa}$ at $1200^{\circ} \mathrm{C}$. The strain maps are highly discontinuous. This is mainly due to the material heterogeneity since similar observations have been reported in Ref. 19 in the elastic domain of a similar material. Nevertheless, in this case, no crack is observed: if the strain fields $\varepsilon_{x x}$ exhibit sharp localisations, the displacement fields $u_{x}$ in Fig. 11 remain almost continuous considering such a heterogeneous material. The strain fields at points $\mathrm{E}$ and $\mathrm{F}$ show also a shift of the isovalue line $\varepsilon_{x x}=0$ towards the compressive area. This is already noticeable at point $\mathrm{E}$ and very pronounced at point $\mathrm{F}$. The shift of this line from the midline of the specimen is about $25 \%$ of the specimen height (cf. Fig. 11) and can be attributed to the asymmetric creep since no damage is put in evidence.

The strain field was then averaged over the $x$-coordinate, between the upper rollers (uniform bending moment), in order to be homogenised and plotted against the $y$-coordinate, Fig. 12. The average strain distribution is almost linear putting in evidence that the Bernoulli assumption is still valid in this experiment. At point E, more than $75 \%$ of the material undergoes a tensile residual strain showing the shift of the neutral axis towards the initially compressed volume. At point $\mathrm{F}$, the position of the iso-line $\varepsilon_{x x}=0$ is the same as at point $\mathrm{E}$. It seems that the position of the neutral axis is already steady at point $\mathrm{E}$.

\section{Discussion}

As verified by Nazaret et al. ${ }^{31}$ the Young's modulus of refractory castables at room temperature is the same under tensile and compressive stresses. The asymmetric strain field measured in the present study is thus mainly due to creep asymmetry since no cracking is observed at $1200^{\circ} \mathrm{C}$. This is not the case at $1030{ }^{\circ} \mathrm{C}$. However it is not straightforward that the iso-value line $\varepsilon_{x x}=0$ measured in this study is the neutral axis, defined usually as the iso-value line $\sigma_{x x}=0$ (axial stress component), equivalent to the iso-value $\varepsilon_{x x}=0$ (elastic strain) in the case of a linear elastic behaviour.

In creep experiment, the instantaneous response of a material subjected to a four-point bending loading is linear elastic. If

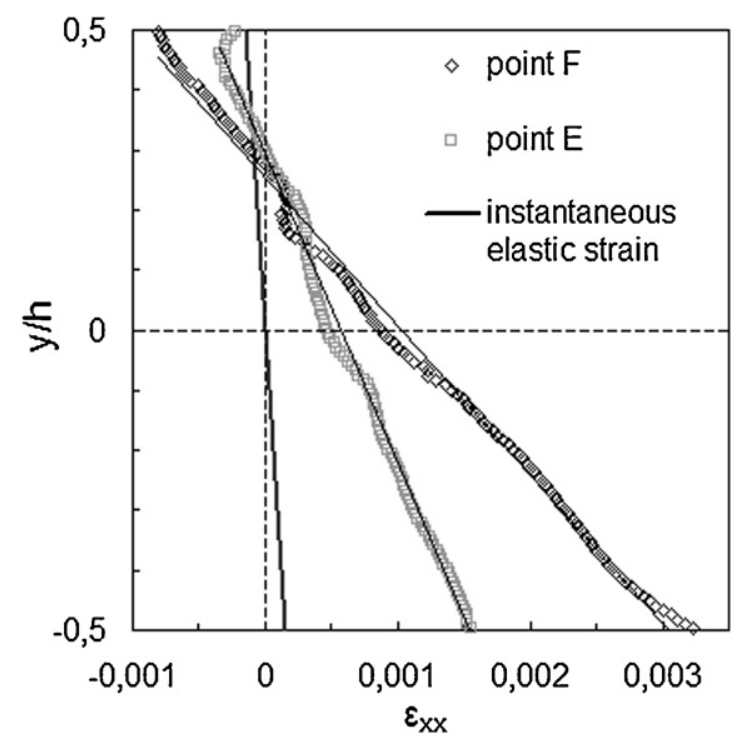

Fig. 12. Permanent strain field measured by 3 D-DIC as a function of the $y$ coordinate in the uniform bending moment area at points E and F. The plotted values are averaged over the horizontal range defined between the upper rollers for each $y$-coordinate value.

the creep behaviour is symmetric, the creep rate increases with the stress according to a power law. As the stress distribution is linear through the thickness, the creep rate distribution through the thickness also follows a power law, leading to a non-linear creep strain distribution. As the total strain remains small, the Bernoulli assumption is still relevant (cf. Fig. 12) and the total strain is thus linear through the thickness. The non-linear creep strain is completed by an elastic strain corresponding to the difference between the linear total strain and the non-linear creep strain. Therefore the stress distribution follows the same nonlinear evolution, resulting in a stress field accommodation due to inelastic strain.

If the creep rate is asymmetric, the same phenomenon takes place, but a faster creep in tension results in a displacement of the neutral axis with time. The moment equilibrium implies higher stresses in the compressed volume (slower creep rate) because it is smaller than the volume subjected to tension. This is illustrated in Fig. 13a using qualitative results of a semi-analytical model from the beam theory (uniaxial stress field, secondary creep, same stress exponent in tension and compression, pre-exponent constant ten times higher in tension, finite differences integration scheme).

This phenomenological description of the stress state evolution implies that part of the material initially compressed under low stresses creeps in a first time under compressive stresses. The same part of the material creeps then under tensile stresses once the neutral axis reaches its location (Fig. 13b). In a first approximation, it could be considered that the creep rate in the vicinity of the neutral axis could be neglected since the stress is very low. At least for short times after beginning the creep experiment, the creep strain is then small compared to the elastic strain and a single definition of the neutral axis can be given, since the iso-value lines zero-strain and zero-stress are coincident. 

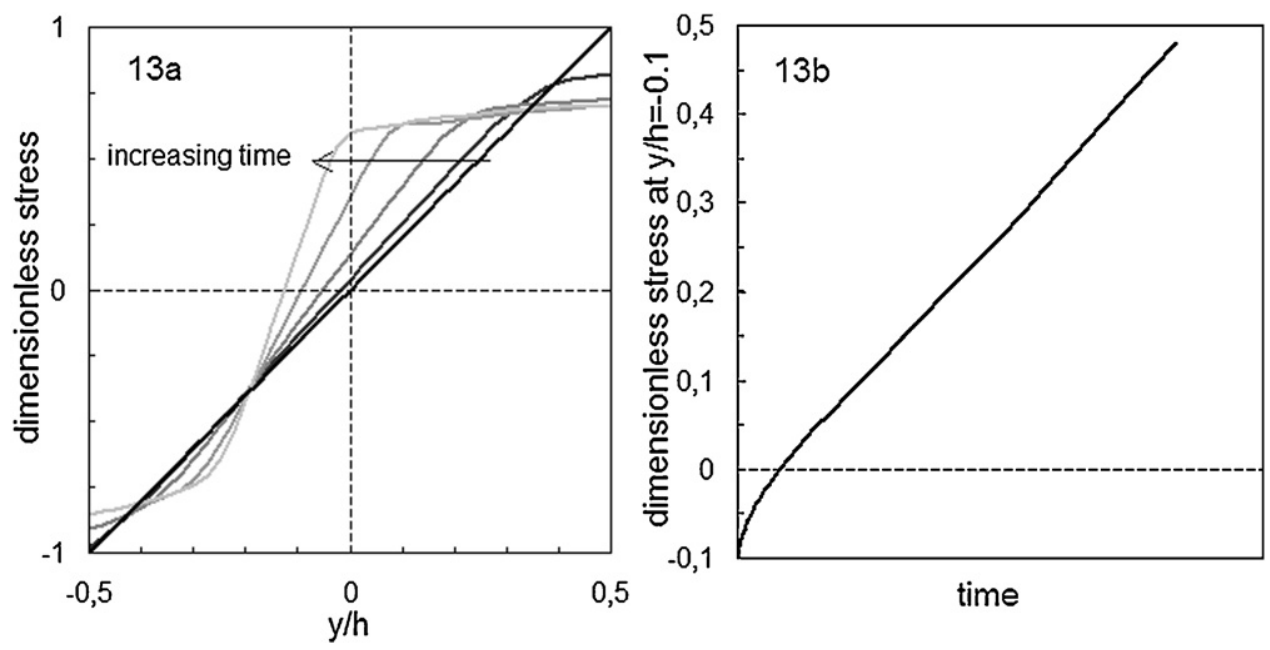

Fig. 13. Dimensionless stress field evolution with time for creep under bending loading (a) and dimensionless stress evolution with time at $y / h=-0.1$ (b).

The strain fields reported previously are measured after elastic unloading and viscous stress relaxation. The material which crept under tensile stresses is subjected after spring-back to compressive stresses and reciprocally. During relaxation the neutral axis may thus undergo a new displacement in the direction of its initial location. However, Fig. 10 shows that both elastic unloading and relaxation amplitudes are small compared to the creep strain. Furthermore the displacement of the neutral axis, located in a low stressed material, can be assumed not to be significant while unloading. In such conditions, the location of the neutral axis measured on relaxed specimen, can be assumed to be the actual location of the iso-value lines zero-strain and zero-stress. However such a measurement does not constitute an intrinsic characterisation of the creep asymmetry since it is not constant with time.

A fine understanding of this phenomena would require a simulation of the state of stress evolution with time, and experimental data are thus mandatory to model more completely the material behaviour. The interest of this experimental result is to provide new data in order to identify from a single test the whole creep behaviour of asymmetric materials. This could be useful to understand how a steady state arises necessarily at a given time of creep. Fig. 12 shows that the neutral axis did not drift significantly between points $\mathrm{E}$ and $\mathrm{F}$. It may indicate that the steady state was almost achieved at point E, i.e. for a short time of creep. The position of the neutral axis in this steady state would provide an intrinsic characteristic of the asymmetry.

\section{Conclusion}

Experimental results are reported in this paper that characterise the asymmetric creep behaviour of a refractory castable at high temperature. Usual four-point bending tests were interrupted in order to carry out full-field strain measurements on the surface of the specimens. At $1030^{\circ} \mathrm{C}$, each specimen underwent cracking preventing any creep interpretation. However, if the temperature is high enough and the stress low enough to prevent cracking, the creep asymmetry can be highlighted by the location of the neutral axis if the latter is different from the middle axis. For short times, the effect of unloading and relaxation on the position of the neutral axis can be neglected since it is located in a low stressed area. However this data evolves with time and as a consequence is not an intrinsic characteristic of the asymmetrical behaviour.

The more significant information provided by this method is the strain field of a single specimen undergoing both tension and compression, allowing to discriminate asymmetry and material variability. New data are provided to feed behaviour law identification. This step is mandatory to model more accurately the material behaviour, simulate the experiment and compare both experimental and simulated data. As well as a validation or assessment of the model limits, a new insight would be possible allowing to define an intrinsic asymmetry parameter that could be directly measured using full-field measurements.

\section{Acknowledgement}

The authors gratefully acknowledge Correlated Solutions for providing Vic-3D ${ }^{\circledR}$ software. Special thanks are expressed to $\mathrm{G}$. Azema and A. Pasquier for specimen preparation and experiments.

\section{References}

1. Hynes A, Doremus R. Theories of creep in ceramics. Crit Rev Solid State Mater Sci 1996;21:129-87.

2. Meléndez-Martinez JJ, Jiménez-Melendo M, Dominguez-Rodriguez A, Wötting G. Creep behaviour of two sintered silicon nitride ceramics. $J$ Eur Ceram Soc 2002;22:2495-9.

3. Kottada RS, Chokshi AH. The high temperature tensile and compressive deformation characteristics of magnesia doped alumina. Acta Mater 2000;48:3905-15.

4. Rosenfield AR, Shetty DK, Duckworth WH. Estimating tensile creep data from flexure data. J Am Ceram Soc 1986;69:108-9.

5. Warshaw SI, Norton FH. Deformation behavior of polycrystalline aluminum oxide. J Am Ceram Soc 1962;45:479-86.

6. Lim HJ, Jung JW, Han DB, Kim KT. A finite element model for asymmetric creep behavior of ceramics. Mater Sci Eng A 1997;224:125-30. 
7. Wereszczak AA, Ferber MK, Kirkland TP, Barnes AS, Frome EL, Menon MN. Asymmetric tensile and compressive creep deformation of hot-isostatically-pressed $\mathrm{Y}_{2} \mathrm{O}_{3}$-doped-Si ${ }_{3} \mathrm{~N}_{4}$. J Eur Ceram Soc 1999;19:227-37.

8. Dryden JR. On the creep in ceramics due to a viscous grain boundary phase. J Mech Phys Solids 2000;48:2115-35.

9. Massard L. Etude du fluage de réfractaires électrofondus du système alumine-zircone-silice. $\mathrm{PhD}$ thesis, Ecole nationale supérieure des Mines de Paris, France; 2005 [in French].

10. Blond E, Schmitt N, Hild F, Blumenfeld Ph, Poirier J. Modelling of high temperature asymmetric creep behavior of ceramics. J Eur Ceram Soc 2005;25:1819-27.

11. Lee DJ, Palley I. Tensile creep in ceramics using four-point bending test. $J$ Mech Sci Technol 1994;8(September (3)):325-31.

12. Lee DJ. Estimating tensile creep rate of ceramics from flexure data. $J$ Eur Ceram Soc 1996;16:1377-83.

13. Peras AY. The flexural creep of refractory materials. Refract Ind Ceram 1977;18:294-7.

14. Timoshenko H. Non-stationary stress distribution in a ceramic bending beam during constant load. Res Mech 1984;10:55-71.

15. Talty PK, Dirks RA. Determination of tensile and compressive creep behaviour of ceramic materials from bend tests. J Mater Sci 1978;13: 580-6.

16. Chen CF, Chuang TJ. Improved analysis for flexural creep with application to SiAlON ceramics. J Am Ceram Soc 1990;73:2366-73.

17. Chuang TJ. Estimation of power-law creep parameters from bend test data. J Mater Sci 1986;21:165-75.

18. Wiederhorn SM, Chuck L, Fuller Jr ER, Tighe NJ. Creep rupture of siliconized silicon carbide. In: Tressler RE, Messing GL, Pantano CG, Newnhan RE, editors. Material science research, tailoring multiphase and composite ceramics, vol. 20. New York: Plenum Press; 1986. p. 755-73.

19. Robert L, Nazaret F, Cutard T, Orteu JJ. Use of 3-D digital image correlation to characterize the mechanical behaviour of a fiber reinforced refractory castable. Exp Mech 2007;47:761-73.
20. Leplay P, Réthoré J, Meille S, Baietto MC. Damage law identification of a quasi brittle ceramic from a bending test using Digital Image Correlation. $J$ Eur Ceram Soc 2012;30:2715-25.

21. Sharma SK, Ko GD, Kang KJ. High temperature creep and tensile properties of alumina formed on Fecralloy foils doped with yttrium. J Eur Ceram Soc 2009;29:355-62.

22. Völkl R, Fischer B. Mechanical testing of ultra-high temperature alloys. Exp Mech 2004;44:121-7.

23. Marzagui $\mathrm{H}$, Cutard T. Characterisation of microstructural evolutions in refractory castables by in situ high temperatures ESEM. J Mater Proc Technol 2004;155-156:1474-81.

24. Sutton MA, Orteu JJ, Schreier HW. Image correlation for shape, motion and deformation measurements: basic concepts, theory and applications. Berlin: Springer; 2009.

25. Delmas A, Le Maoult Y, Buchlin JM, Sentenac T, Orteu JJ. Shape and temperature field distortions induced by convective effect on hot object in the near infrared and infrared spectral bands. In: Proc. of the QIRT 10. 2010. p. 97-104.

26. Grant BMB, Stone HJ, Withers PJ, Preuss M. High-temperature strain field measurement using digital image correlation. J Strain Anal Eng Design 2009;44:263-71.

27. Badulescu C, Grédiac M, Mathias JD. Investigation of the grid method for accurate in-plane strain measurement. Meas Sci Technol 2009;20:095102.

28. Roux S, Hild F. Stress intensity factor measurements from digital image correlation: post-processing and integrated approaches. Int J Fract 2006;140:141-57.

29. Bornert M, Brémand F, Doumalin P, Dupré JC, Fazzini M, Grédiac M, et al. Assessment of Digital Image Correlation measurement errors: methodology and results. Exp Mech 2009;49:353-70.

30. Vic-3D software. Correlated Solutions Incorporated; 2011. http://www.correlatedsolutions.com/

31. Nazaret F, Marzagui H, Cutard T. Influence of the mechanical behaviour specificities of damaged refractory castables on the Young's modulus determination. J Eur Ceram Soc 2006;26:1429-38. 